\title{
The evolution of adjuvant surgical tools in aiding maximal safe anatomical resection
}

\author{
Gavin W. Britz, MD, MPH, MBA \\ Department of Neurosurgery, Houston Methodist Hospital and Neurological Institute, Houston, Texas
}

$\mathrm{A}$ s Luzzi and colleagues state in their article, the theoretical advantages of augmented reality (AR) with diffusion tensor imaging (DTI)-based highdefinition fiber tractography (HDFT) and sodium fluorescein (HDFT-F) in high-grade glioma (HGG) surgery have not been investigated. Luzzi et al. aimed to evaluate the safety and efficacy profiles of HDFT-F microscopebased AR cytoreductive surgery for newly diagnosed supratentorial HGGs. ${ }^{1}$ A total of 54 patients underwent surgery using the AR HDFT-F technique, and 63 underwent conventional white-light surgery assisted by infrared neuronavigation. It was found that the study group had a better extent of resection (EOR) and progression-free survival rate, and, therefore, the authors concluded that $A R$ HDFT-F-assisted surgery is safe and effective in maximizing the EOR. For oncological surgery in solid tumors, in general, the goal is to remove all tumor tissue, often with a circumscribing rim of normal tissue called the surgical margin. ${ }^{2,3}$ In neurosurgery, however, resection of peritumoral grossly normal tissue is seldom achievable, as both high- and low-grade gliomas are infiltrative lesions. Gross-total resection (GTR) for HGGs is defined as the removal of all contrast-enhancing tissue, ${ }^{4-6}$ even though HGGs are believed to have microscopic dissemination.? Despite the dissemination, it has been demonstrated that the absolute tumor residual (as distinct from EOR) for surgically resected tumor is consistently inversely correlated with overall survival ${ }^{8,9}$ and progression of the disease..$^{10} \mathrm{It}$ has also been noted that maximal safe resection improves seizure control. ${ }^{11}$ Therefore, obtaining a maximal safe anatomical resection has become the goal of tumor operations regardless of the grade. This has been taken further with the concept of achieving a supratotal resection in which a wider gross tumor margin is achieved surgically. This not only has been described but also has been demonstrated to have positive results regarding the progression-free survival rate despite the infiltrative nature of the lesions. ${ }^{12}$
This is probably related to having less tumor burden that is then more responsive to radiation therapy, chemotherapy, and even the body's own immune system.

To achieve the goal of GTR and even a supratotal resection, it is required that the surgeon use multiple adjuvant surgical tools that were not available in earlier periods of neurosurgery. These tools make it possible for the surgeon to remove the tumor safely by understanding the anatomical location of functional cortex as well as important deep white matter tracts. This allows the tumor to be removed without damaging these important structures. Preoperative functional MRI (fMRI) imaging and DTI are used to preserve both functional cortex and eloquent white matter tracts to achieve this goal. Neuronavigation-which gives the surgeon a real-time anatomical location of normal anatomy, tumor, and important structures based on imaginghas revolutionized operative neuro-oncology, particularly when integrating preoperative fMRI and DTI. ${ }^{13,14}$ This allows the surgeon to combine the visualization of normal anatomy, important functional cortex, and important deep white matter tracts to plan the operation and prevent damage to these areas. Another tool is the awake craniotomy, with cortical and subcortical stimulation mapping, which allows the surgeon to monitor the patient's clinical status, in addition to electrophysiological mapping that allows for a safer and more effective resection without having postoperative surprises regarding functional outcome. ${ }^{15}$ Fiveaminolevulinic acid (5-ALA), a precursor in the biosynthetic pathway for protoporphyrin IX and heme, has also been used to improve detection of residual tumor cells at the brain-tumor interface. ${ }^{16}$ This technique operates on the premise that, compared with normal cells, tumor cells exhibit greater uptake of 5-ALA and protoporphyrin IX formation, and, therefore, it provides visualization of normal brain versus tumor. Obtaining intraoperative MRI to ensure that maximal resection is achieved before leaving the operating room is another technique. ${ }^{17,18}$ In addition to 
intraoperative MRI, efforts have been made to use CT and ultrasonography imaging intraoperatively to guide tumor resection. ${ }^{19}$ This evolution of adjuvant surgical tools to obtain safer and larger resection is evolving. Luzzi et al. have used a modification of the current technology described earlier by using AR HDFT-F to aid in resection and to improve both the EOR and progression-free survival rate, as well as in optimizing patient functional outcomes. The evidence of better postoperative Neurological Assessment in Neuro-Oncology (NANO) scores in the study group demonstrated this in achieving better overall functional outcomes and quality of life in glioma surgery. The EOR was significantly higher with the AR HDFT-F assistance, leading to a resection rate of $98 \%$ in $85 \%$ of the patients. These data agree with the greater intraoperative spatial understanding of the fiber tract course, which ultimately enables surgeons to prevent premature stopping of the surgery and obtain an increased EOR and a longer progression-free survival rate, as observed in the study group. Technological advancements will continue in glioma surgery until the field is changed by nonsurgical options in the treatment of this condition.

https://thejns.org/doi/abs/10.3171/2021.5.FOCUS21321

\section{References}

1. Luzzi S, Lucifero AG, Martinelli A, Del Maestro M, Savioli $\mathrm{G}$, et al. Supratentorial high-grade gliomas: maximal safe anatomical resection guided by augmented reality high-definition fiber tractography and fluorescein. Neurosurg Focus. 2021;51(2):E5.

2. Halsted WS. I. The results of operations for the cure of cancer of the breast performed at the Johns Hopkins Hospital from June, 1889, to January, 1894. Ann Surg. 1894;20(5):497-555.

3. Schulman H, Cavanagh D. Intraepithelial carcinoma of the cervix. The predictability of residual carcinoma in the uterus from microscopic study of the margins of the cone biopsy specimen. Cancer. 1961;14:795-800.

4. Claus EB, Horlacher A, Hsu L, Schwartz RB, Dello-Iacono $\mathrm{D}$, et al. Survival rates in patients with low-grade glioma after intraoperative magnetic resonance image guidance. Cancer. 2005;103(6):1227-1233.

5. Hollon T, Nguyen V, Smith BW, Lewis S, Junck L, Orringer DA. Supratentorial hemispheric ependymomas: an analysis of 109 adults for survival and prognostic factors. J Neurosurg. 2016;125(2):410-418.

6. Incekara F, Olubiyi O, Ozdemir A, Lee T, Rigolo L, Golby A. The value of pre- and intraoperative adjuncts on the extent of resection of hemispheric low-grade gliomas: a retrospective analysis. J Neurol Surg A Cent Eur Neurosurg. 2016;77(2): 79-87.

7. Kelly PJ, Daumas-Duport C, Kispert DB, Kall BA, Scheithauer BW, Illig JJ. Imaging-based stereotaxic serial biopsies in untreated intracranial glial neoplasms. J Neurosurg. 1987;66(6):865-874.

8. Capelle L, Fontaine D, Mandonnet E, Taillandier L, Golmard $\mathrm{JL}$, et al. Spontaneous and therapeutic prognostic factors in adult hemispheric World Health Organization Grade II gliomas: a series of 1097 cases: clinical article. J Neurosurg. 2013;118(6):1157-1168.
9. Jakola AS, Myrmel KS, Kloster R, Torp SH, Lindal S, et al. Comparison of a strategy favoring early surgical resection vs a strategy favoring watchful waiting in low-grade gliomas. JAMA. 2012;308(18):1881-1888.

10. Keles GE, Anderson B, Berger MS. The effect of extent of resection on time to tumor progression and survival in patients with glioblastoma multiforme of the cerebral hemisphere. Surg Neurol. 1999;52(4):371-379.

11. Smith JS, Chang EF, Lamborn KR, Chang SM, Prados MD, et al. Role of extent of resection in the long-term outcome of low-grade hemispheric gliomas. J Clin Oncol. 2008;26(8): 1338-1345.

12. Duffau H. Long-term outcomes after supratotal resection of diffuse low-grade gliomas: a consecutive series with 11-year follow-up. Acta Neurochir (Wien). 2016;158(1):51-58.

13. D'A mico RS, Englander ZK, Canoll P, Bruce JN. Extent of resection in glioma-a review of the cutting edge. World Neurosurg. 2017;103:538-549.

14. Berntsen EM, Gulati S, Solheim O, Kvistad KA, Torp SH, et al. Functional magnetic resonance imaging and diffusion tensor tractography incorporated into an intraoperative 3-dimensional ultrasound-based neuronavigation system: impact on therapeutic strategies, extent of resection, and clinical outcome. Neurosurgery. 2010;67(2):251-264.

15. Duffau H, Lopes M, Arthuis F, Bitar A, Sichez JP, et al. Contribution of intraoperative electrical stimulations in surgery of low grade gliomas: a comparative study between two series without (1985-96) and with (1996-2003) functional mapping in the same institution. J Neurol Neurosurg Psychiatry. 2005;76(6):845-851.

16. Acerbi F, Broggi M, Eoli M, Anghileri E, Cavallo C, et al. Is fluorescein-guided technique able to help in resection of high-grade gliomas? Neurosurg Focus. 2014;36(2):E5.

17. Leuthardt EC, Lim CC, Shah MN, Evans JA, Rich KM, et al. Use of movable high-field-strength intraoperative magnetic resonance imaging with awake craniotomies for resection of gliomas: preliminary experience. Neurosurgery. 2011;69(1): 194-206.

18. Lu J, Wu J, Yao C, Zhuang D, Qiu T, et al. Awake language mapping and 3-Tesla intraoperative MRI-guided volumetric resection for gliomas in language areas. J Clin Neurosci. 2013;20(9):1280-1287.

19. Hosoda T, Takeuchi H, Hashimoto N, Kitai R, Arishima H, et al. Usefulness of intraoperative computed tomography in surgery for low-grade gliomas: a comparative study between two series without and with intraoperative computed tomography. Neurol Med Chir (Tokyo). 2011;51(7):490-495.

\section{Disclosures}

The author reports no conflict of interest concerning the materials or methods used in this study or the findings specified in this paper.

\section{Correspondence}

Gavin W. Britz: gbritz@houstonmethodist.org.

\section{INCLUDE WHEN CITING}

DOI: 10.3171/2021.5.FOCUS21321. 